DOI 10.37882/2223-2982.2021.12.16

\title{
КОНЦЕПТ ЖИЗНЬ В РУССКОЙ И НЕМЕЦКОЙ ЛИНГВОКУЛЬТУРАХ
}

\section{THE CONCEPT OF LIFE IN RUSSIAN AND GERMAN LINGUISTIC CULTURES}

O Litvjak

Summary: The article suggests a comparative analysis of the concept of LEBEN and considers it in the realities of German and Russian linguistic cultures. Language, being an inseparable part of any nation, creates its own personal perception of the world and conducts it through its own way of conceptualization, sometimes interpreting the same concepts from different sides. The conceptual picture of the world, which is mostly tied to knowledge, thoughts and ideas about the world, is displayed in various significant moments of all human cognitive activity, which is already closely connected with further activities.

Keywords: concept, life, linguaculture, conceptual meaning, sema, conceptual picture of the world, language, concept of life, essence, being, cognition, knowledge, abstractness, life path.

\section{Постановка проблемы}

И зучение концептов всегда подводит к тому, что разная нация по-своему определяет тот или иной концепт, так как, каждая нация имеет свой особый и неповторимый менталитет, который имеет свойство придавать словам свои значения и понятия, даже если смысл остаётся тем же. В данной работе идёт сравнение концепта LEBEN в немецкой и русской лингвокультуре, его рассмотрение с философской стороны, как понятия абстрактного и отделимого от человека, определяющего его пусть и выступающего в роли мерилы времени. Помимо этого, концепт LEBEN является сложным многоуровневым комплексом, который способен собрать воедино хаотичность мира.

\section{Анализ исслеАованной литературы}

Основой для написания данной научной статьи послужили работы отечественных и зарубежных исследователей Кубрякова Е.С., Карасик В.И., Красных В.В., Телия и др.

Цель данной работы исследование концептосферы LEBEN в реалиях немецкой и русской лингвокультур, определение ее места и роли в формировании немецкой и русской национальной культуры.

\section{Изложение основного материала}

Язык является важнейшей составляющей национального сознания общества, выражающий особенности менталитета. Подразумевая то, что каждая нация имеет
Литвяк Олеся Валерьевна

К.филол.н., доцент, Крымский инженерно-педагогический университет имени Февзи Якубова, Симферополь ole.litviak@yandex.ru

Аннотация: В статье предлагается провести сопоставительный анализ концепта LEBEN и рассмотреть его в реалиях немецкой и русской лингвокультур. Язык, являясь неотделимой частью любой нации, создает свое личное мировосприятие и проводит его сквозь свой способ концептуализации, трактуя порой одинаковые концепты понятий с разных сторон. Концептуальная картина мира имеющая, по большей степени, привязку к знаниям, мыслям и представлениям о мире, отображается в разных значимых моментах всей познавательной деятельности человека, которая уже тесно связана с дальнейшими видами деятельности.

Ключевые слова: концепт, жизнь, лингвокультура, концептуальное значение, сема, концептуальная картина мира, язык, концепт жизни, сущность, бытие, познание, знания, абстрактность, жизненный путь.

свое собственное восприятие мира вокруг себя и показывает его сквозь призму своих особенностей культуры, то есть концептуалиризует.

Термин "концепт" уже давно глубоко укоренился в разных областях жизни, начиная конгнивистикой и заканчивая лингвистикой.

Однако, не существует единственного и четкого понятия "концепт", так, например, Н.Д. Арутюнова полагает, что концепт имеет собственный статус, отражает понятийное содержание языковых явлений и является понятием практической (обыденной) философии. Концепты образуют «культурный слой, посредничающий между человеком и миром» [Арутюнова: 1999].

По Е.С. Кубряковой концепт понимается как «многомерный мыслительный конструкт, отражающий процесс познания мира, результаты человеческой деятельности, его опыт и знания о мире, хранящий информацию о нем» [12].

Согласно В.И. Карасику, концепт состоит из трех компонентов - понятийного, образного и ценностного [7]. Концепт в отличие от понятия не только мыслится, но и переживается. Из этого следует, что его объем шире объема понятия. Концепт включает в себя само понятие, являющееся в свою очередь его обязательным ядерным компонентом.

Но, как правило, термин "концепт" репрезентуют следующим: концепт - это отражение фактов реальности, который завязан на познавательной деятельности людей. 
Концепты формируют не что иное, как основу мира, которая несет в себе информацию для того, чтобы осуществить мыслительную деятельность, а также собрать воедино и сформировать знания человека об окружающем его мире.

Существует тематическая классификация концептов. По тематическому признаку В.А. Маслова разделяет все концепты на девять основных групп:

1. мир (пространство, время, родина...);

2. природа (вода, огонь, дерево...);

3. нравственные концепты (совесть, стыд...);

4. представления о человеке (гений, юродивый, интеллигент...);

5. социальные понятия и отношения (свобода, война...);

6. эмоциональные концепты (счастье, радость...);

7. артефакты (дом, храм, колокол...);

8. научные знания (филология, математика...);

9. искусство (живопись, музыка, скульптура...) [13]

Ментальный конструкт концепта содержать в себе следующие базовые характеристики: иерархичность, бесконечность, антиномичность.

Иерархичность значит, что концепты очень тесно связаны между собой и все они помогают сформировать языковую картину мира. Бесконечность подразумевает, что концепт - это постоянно существующее понятие, чье содержание является нескончаемым и постоянно пополняемым.

Антиномичность - это возможность концепта включать в себя два противоречащих понятия и мнения об одном и том же, однако, каждое мнение и понятие имеет своё логическое обоснование.

Структуру концепта можно обнародовать с помощью анализа языковых средств, через которые он презентован. Анализ помогает раскрыть структуру рассматриваемого концепта, описать специфику и определить степень важности для всей языковой картины мира.

В данной работе рассматривается концепт LEBEN в реалиях русской и немецкой лингвокультур. В первую очередь важно определить положение концепта LEBEN в формировании немецкой и русской национальной культуры.

В основе вербализации концепта LEBEN в немецкой лингвокультуре в первую очередь выступают следующие экспоненты: сема «жизнь» воспринимается как среда, которая состоит из нескольких уровней с присущими для них качествами:

а) объемность, глубина, возможность спрятаться в этой среде, растаять в нем: Das Leben und Treiben; das blühende Leben; das Leben bejahen; so ist ein Leben [6, 672];

б) возможность существования в самых разнообразных условиях иногда даже противоположных: das nackte Leben; das schlechte Leben; das arme Leben $[6,362]$;

в) возможность (при бесконечности расширения) потери формы, отсутствие рамок существования приграничных зон: im Leben und Sterben; an Leben und Tod entscheiden; leben und Weben; man lebt nur einmal in der Welt [6, 362-369].

Концепт LEBEN здесь выступает как многоуровневый комплекс, собирающий и сохраняющий все нюансы внутренней организации. Это может быть рассмотрено с двух сторон: положительной и отрицательной, то есть, с помощью собирающих образов, образных выражений концепт LEBEN вербализуется, а соответственно вокруг него формируются некоторые моральные принципы, жертвенность ради близких и своих целей, согласно В.Н. Телии, „вторичное название отдает часть информации о типичном явлении в новом названии, храня некоторые особенности подобно гештальт-структуре“ [14, 127]. Например: mit dem Leben bezahlen, nicht leben und nicht sterben, sein Leben einsetzen (dransetzen, lassen, wagen), sein Leben lassen müssen $[6,363]$.

Также концепт "жизнь" связывается не только с понятием "жить" в привычном для нас значении, а также и с познавательной деятельностью, то есть, жизнь понимается как путь, знания и процесс её изучения. Неоспоримо важен тот факт, что развитие познавательной деятельности направленно непосредственно на осознание и постижение окружающего мира - и человеческого, и невидимого для человека. Базируясь на этом “жизнь" является необходимой каждому человеку. Именно отсюда пошли такие известные выражения: Das Leben geht seinen Gang, So ist das Leben, Das Leben verrint [6, 364-365].

Само определение концепта "жизнь" также обладает своими определёнными свойствами. Концепт "жизнь" воспринимается, как мерила самого существования, она словно часы, измеряющие её длительность и отделяющие время и сам процесс самопознания состоит из общих знаний о всём мире, которые все подчиняются поиску ценностного начала, который может собрать и упорядочить весь возникший хаос в мире: überall herrscht Leben und Freude, mein Leben gleicht einer aufgezogenen Uhr, Die Straßen sind voller Leben, Das ist aus dem Leben gegriffen $[17,673]$.

Концепт LEBEN является абстрактным, а также играет роль своего рода необъятного и невидомого с присущими ему качествами, например, со способностью дать существование всему живому, при этом выступая как мир, что может быть создан в абсолютно любом простран- 
стве, помимо этого оно может существовать отдельно от субъектов, пусть и всем известно, что в какой-то мере контролируется им: Leben und Weben, an Leben und Tod entscheiden [6, 362].

В отдельных случаях лексема LEBEN может десемнатизироваться и, впоследствии, она приобретает отрицательное значение. В негативном ключе, она представляет из себя пустоту, бездушие, абсолютную тишину и, естественно, смерть: sein Leben lassen müssen, ums Leben kommen, mit dem Leben bezahlen $[6,363]$.

Обращаясь к изображению концепта "жизнь" в русских реалиях, то самая частотная концептуальная метафора: ЖИЗНь - ПУТь. Как отмечает Н.В. Павлович, это «одна из самых продуктивных метафорических парадигм 18-19 веков» (Павлович, 1995, 21). Но и поныне этот фрагмент языковой картины мира является актуальным: Человек вступает в жизнь, идет по жизни, уходит из жизни.

Жизнь в русской языковой картине мире также предстает в виде ценности. Именно поэтому, обращаясь к кому-либо самому дорогому, мы говорим «Жизнь моя», то есть, мы предполагаем, что данный человек для нас бесценен. Но в наши дни даже у жизни появилась цена, то есть, произошло обесценивание жизни, ее можно оценить в деньгах, измерить по шкале материальных ценностей: «Цены на автомобили растут, а цена на человеческую жизнь падает...»

ЖИЗНЬ - СОБСТВЕННОСТЬ, принадлежность человека. Жизнь человеку могут дать (подарить) его родители. В Толковом словаре В.И. Даля мы находим поговорку: жизнь дает один только бог, а отнимает всякая гадина. В современной публицистике данная концептуальная метафора актуализируется, например, таким образом: «Жизнь, подаренная журналистом».

Помимо этого, жизнь выступает также в роли учителя, помогающего людям искать свою дорогу, направляющем и помогающем избежать уже совершенных ранее ошибок: «Суровая армейская жизнь, побросала офицера-десантника по дальним гарнизонам, научила его не обращать внимания на бытовые трудности»; «Всему остальному жизнь научила»

Концепт ЖИЗНь в русской лингвокультуре выступает как в положительном ключе, как, например, справедливая судья, которая не делит мир на только черное и белое, поэтому и может рассудить справедливо две столкнувшиеся души: «Жизнь рассудила иначе» (Новые известия №199), но также этот концепт может нести в себе и негативное начало, например, «В моей смерти прошу винить мою жизнь».

Основываясь на выше написанном, можно опреде- лить, что концепт LEBEN в немецкой и в русской лингвокультуре весьма схож в его понимании, так как, обладает схожими между собой определениями самого концепта. Например, в немецкой и в русской лингвокультурах концепт LEBEN тесно связывается с познавательной деятельностью и поучительным характером, то есть, выступая источником знаний, наставником, который может направить на нужный путь, уберечь от ошибок будущего, если верно понять и двигаться в заданном им направлении. В произведениях чаще всего концепт LEBEN привязан именно к данному определению, так как, герои произведения в течении их жизненного пути совершают ошибки, получают опыт и знания.

Для полной характеристики концепта LEBEN в немецкой и русской лингвокультурах стоит обратиться к анализу парадигматических, синтагматических и ассоциативных связей концепта. Очень важным аспектом отношений для анализируемого концепта является синонимическая пара для концепта LEBEN.

В немецкой лингвокультуре ведущими семами являются понятия das Dasein и das Wesen, в русской лингвокультуре они отображаются как СУЩЕСТВОВАНИЕ и БЫТИЕ. Данные семы помогли выявить ведущие когнитивные признаки концепта LEBEN немецкой и русской лингвокультуре.

В первую очередь, это абстрактное понятие, которое представляет из себя путь, который на неопределенный отрезок времени позволяет начать собирать опыт, накапливать знания и двигаться вперед, чтобы в полной мере познать мир, но не только реальный, доступный нашему взгляду, но и невидимый. Сама жизнь выступает мерилом времени, что также привязано к данному концепту. Время, которое было дано жизнью, также привязано к поиску её смысла, самопознанию и духовному обогащению личности.

Вербализация данного концепта в немецкой и русской лингвокультурах также приобретает новое значение, помогая собрать вокруг концепта моральные принципы, жертвенность присущую людям и этим самым подчеркивая ценность жизни в обеих лингвокультурах. Жизнь изображается очень хрупкой, то есть, жизненный путь можно оборвать в любой момент, так и не дойдя к его логическому завершению, собрав достаточно знаний, тем самым достигнув самопознания и набравшись опыта от своего учителя - жизни. Неоднократно подчеркивается то, как, на самом деле, быстро пролетает сама жизнь, а в частности, определенные её отрезки, например, молодость: Des Lebens Falling kehrt nie mehr zuruck.

Жизнь является сложным феноменом, который обладает весьма противоречивыми характеристиками. В немецкой и русской лингвокультурах концепт LEBEN 
по большей степени выступает в положительном ключе, как наставник, как судья и как абсолютно абстрактная сущность, которая может быть и ведущей и ведомой. С одной стороны, она имеет непосредственное воздействие на человека, то есть, она может наградить его, наказать, причинить боль или же, наоборот, сделать самым счастливым, но с другой стороны именно человек сам корректирует свою жизнь, подстраивая её под свой ритм и желания.

На основе данного анализа, можно прийти к выводу, что концепт LEBEN может рассматриваться с разных сторон: абстрактно-философских, интеллектуально-познавательных и метафорических, однако само понимание данного концепта в немецкой и русской лингвокультурах очень схоже.

\section{ЛИТЕРАТУРА}

1. Анищенко А.В. концепт "Zorn” в пословично-поговорочном фонде немецкого языка. // теоретическая и прикладная лингвистика. Выпуск 2. Язык и социальная среда. Воронеж. Изд-во ВГту, 2000.C.78-89// URL: http://eidos.rsl.ru (Режим доступа: 28. 04. 2021)

2. Agricola Erhard. Wörter und Wendungen. Wörter zum deutschen Sprachgebrauch. Leipzig, 1972. S. 387-388.

3. Küpper U. Wörterbuch der deutschen Umgangssprache. Stuttgart, 1987. S. 488-489.

4. Küpper U. Wörterbuch der deutschen Umgangssprache. Stuttgart, 1987. S. 488-489.

5. Paffen K.A. Deutsch-russisches Satzlexikon: in 3B. Leipzig, 1970. Band 2. S. 672-673.

6. Бинович Л.Э., Гришин Н.Н, Немецко-русский фразеологический словарь. М., 1975. С. 362-369.

7. Карасик В. И. Культурные доминанты в языке // Языковая личность: культурные концепты. Волгоград-Архангельск. 1996. С.3-16

8. Концепт «Жизнь/Leben» как фрагмент языковой картины немецкого этноса // Gigabaza.ru URL: https://gigabaza.ru/doc/38517.html (дата обращения: 22.09.2021).

9. Концепт «Жизнь»: анализ и интерпретация // CYBERLENINKA URL: https://cyberleninka.ru/article/n/kontsept-zhizn-analiz-i-interpretatsiya (дата обращения: 22.09.2021).

10. Красных В.В. От концепта к тексту и обратно (к вопросу о психолингвистике текста) // Вестник МГУ. 1998. № 1.

11. Кубрякова Г.В., Демьянков В.З., Панкрац Ю.Г, Лузина Л.Г. Краткий словарь когнитивных терминов. М., 1996. С. 90

12. Кубрякова Е.С. Язык и знание. М., 2004. С. 313.

13. Маслова В.А. Введение в когнитивную лингвистику : учеб. пособие. М. : Флинта : Наука, 2004. 296 с.

14. Телия В.Н. Русская фразеология. Семантический, прагматический и лингвокультурологический аспекты. М., 1996. С. 127.

( ) Литвяк Олеся Валерьевна (ole.litviak@yandex.ru). 